\title{
Identificación y caracterización del agente causal de la "enfermedad de petri " de la vid (Vitis vinifera L.) en el Perú
}

\author{
Identification and characterization of the agent causing "petri disease" of the grapevine (Vitis \\ vinifera L.) in Peru
}

Cesar Romero Rivas ${ }^{1}$; Carlos Cadenas Giraldo ${ }^{2}$

\begin{abstract}
Resumen
Desde el año 2005 se ha observado, en plantaciones de vid de diversas zonas del Perú, plantas jóvenes con síntomas de la Enfermedad de Petri. Se colectaron muestras de plantas de las provincias de Ica y Pisco y se aisló e identificó al hongo Phaeoacremonium parasiticum (Ajello, Georg \& C.J.K. Wang) W. Gams, Crous \& M.J. Wingf. Se evaluó la sensibilidad, en laboratorio, de P. parasiticum: a) a productos químicos mediante la técnica de alimento envenenado y se observó que el pirimetanil y el sulfato de cobre pentahidratado inhiben su crecimiento en un $100 \%$ y el fosetil aluminio en un $91,3 \%$ y b) a controladores biológicos mediante la técnica de enfrentamiento dual con Trichoderma harzianum, Trichoderma lignorum y Bacillus subtilis y se observó que los tres controladores detienen el crecimiento de P. parasiticum.
\end{abstract}

Palabras clave: Phaeoacremonium parasiticum; Vitis vinifera; Enfermedad de Petri.

\begin{abstract}
Since 2005 it has been observed in plantations of vine from different areas of Peru, young plants with symptoms of Petri disease. Plant samples were collected from the provinces of Ica and Pisco, and the fungus Phaeoacremonium parasiticum (Ajello, Georg \& C.J.K. Wang) was isolated and identified W. Gams, Crous \& M.J. Wingf. Under laboratory conditions, we evaluated the sensitivity of P. parasiticum: a) to chemical products using poisoned food technique and it was found that both, pyrimethanil and copper sulfate pentahydrate inhibited its growth in $100 \%$ and Fosetil Aluminium in 91,3 $\%$, and b) to biological controllers by the technique of dual confrontation with Trichoderma harzianum, Trichoderma lignorum and Bacillus subtilis and it was found the three controllers stop the growth of P. parasiticum.
\end{abstract}

Keywords: Phaeoacremonium parasiticum; Vitis vinifera; Petri disease.

\section{Introducción}

La vid (Vitis vinifera) es una de las especies cultivadas más antiguas e importantes a nivel mundial y que es extensamente cultivada en muchos países del mundo. En el Perú, el cultivo de vid se ha venido realizando tradicionalmente en los Departamentos de Lima, Ica, Arequipa, Moquegua, Tacna y, en los últimos años, la región de La Libertad ha incrementado notablemente su producción. Se ha introducido también en el departamento de Piura donde las áreas sembradas vienen incrementándose notablemente.

La Enfermedad de Petri de la vid fue conocida con diversos nombres, hasta el año 2001 cuando, en la Asamblea General del Segundo Seminario Internacional de Enfermedades del Tronco de la Vid, los asistentes acordaron en llamarlo oficialmente como se le conoce ahora en honor a Lionello Petri, que fue el primero en publicar sobre el tema en el año 1912 (Eskalen y Gubler,
2001; Porter, 2005). Esta enfermedad se encuentra principalmente asociada a plantaciones jóvenes y causa pérdidas importantes de plantas jóvenes en viñedos recién instalados (Scheck, Vásquez y Gubler, 1998; Mugnai, Graniti y Surico, 1999; Pascoe y Cottral, 2000). Los síntomas que se observan en las plantas de vid son crecimiento débil y lento, entrenudos más cortos, menor masa foliar, amarilleamiento internerval en las hojas seguido de necrosis y defoliación temprana; asimismo, se observa un menor desarrollo radicular y la presencia de lesiones necróticas en las raíces. Otro síntoma es el fracaso de los injertos en el primer año. Al hacer cortes transversales y longitudinales de los tallos y ramas pueden observarse necrosis internas, en forma de puntos negros y estrías de marrón oscuro a negro. La ruptura de los vasos del xilema generalmente libera un líquido negro. Las plantas infectadas pueden llegar a morir (Mugnai et al., 1999; Morton, 2000; Pascoe y Cottral, 2000; Mostert, Halleen, Fourie y Crous, 2006).

\footnotetext{
1 Profesor Principal de la Escuela de Formación Profesional en Agronomía. Universidad Nacional Daniel Alcides Carrión, Oxapampa, Perú. Email: cerori@msn.com

2 Profesor Principal del Departamento Académico de Fitopatología. Universidad Nacional Agraria La Molina, Lima, Perú. Email: ccadenas@lamolina.edu.pe
} 
La Enfermedad de Petri es causada por los hongos Phaeomoniella chlamydospora (W. Gams, Crous \& M.J. Wingf. \& L. Mugnai) Crous \& W. Gams y varias especies de Phaeoacremonium W. Gams, Crous \& M.J. Wingf. (Scheck, Vásquez y Gubler, 1998; Mugnai et al., 1999). El género Phaeoacremonium agrupa muchas especies que afectan tanto a plantas como a humanos y a animales; hasta el momento, de varias especies vegetales y en vid, se han aislado e identificado 13, de las cuales la especie tipo es Phaeoacremonium parasiticum (Mostert et al., 2006).

El control de los hongos que causan la Enfermedad de Petri se viene investigando en los diferentes países donde se ha detectado. Los benzimidazoles son fungicidas eficaces contra muchos tipos de enfermedades fungosas y estos compuestos interfieren con la división nuclear de los hongos. Los triazoles y los imidazoles son inhibidores de la síntesis del ergosterol, que es esterol presente en las membranas celulares de los hongos. El fosetil alumnio es muy eficaz contra enfermedades foliares, radiculares y del tallo causadas por Oomycetos. Se ha reportado que el fosetil aluminio estimula las reacciones de defensa y la síntesis de fitoalexinas. Las anilinopirimidinas inhiben la biosíntesis de metionina bloqueando la excreción de enzimas hidrolíticas que participan en el proceso de patogénesis. El fosfonato de potasio es un producto químico de traslocación sistémica utilizado para proteger las plantas contra patógenos oomycetos; induce una rápida respuesta de defensa localizada normalmente en plantas sensibles que son similares a las observadas en una interacción incompatible. En lo referente a los fungicidas formulados a base de cobre, la acción tóxica del cobre se atribuye a su capacidad para desnaturalizar las proteínas celulares y para desactivar el sistema enzimático de hongos y algas (La Torre, 1989; Fritz, Lanen, Colas y Leroux, 1997; OMRI, 2001; Agrios, 2005; Daniel, 2006).

Los controladores biológicos comercialmente disponibles para el control de las enfermedades de las plantas son hongos del género Trichoderma y la bacteria Bacillus subtilis. Los principales mecanismos de control de los agentes biocontroladores incluyen el micoparasitismo, la antibiosis y la competencia por los recursos y el espacio. Las especies del género Trichoderma se han conocido por lo menos desde la década de 1920 por su capacidad de actuar como agentes de biocontrol contra patógenos de plantas y diversos trabajos de investigación demuestran que los efectos de las especies de Trichoderma en las plantas es que funcionan como inductores de la resistencia sistémica o localizada, promueven el crecimiento de la planta y propician la mejor absorción de nutrientes. Los estudios de micoparasitismo de los Trichoderma han demostrado que estos hongos producen una rica mezcla de enzimas antifúngicas, incluyendo las quitinasas y las $\beta-1,3$ glucanasas. Estas enzimas son de carácter sinérgico entre sí, con otras enzimas antifúngicas y con otros materiales (Harman, 2006).

La bacteria Bacillus subtilis está frecuentemente en los suelos y se ha encontrado en una gran variedad de hábitats de todo el mundo. La cepa QST 713 de B. subtilis es conocida por ser antagonista de muchos hongos patógenos de plantas. Este antagonismo lo logra de diversas maneras que incluye la competencia de nutrientes, la exclusión de sitios, la colonización y el acoplamiento de las bacterias a los hongos patógenos. AgraQuest, la empresa productora de la cepa QST 713, informa que esta ha mostrado inducir en las plantas resistencia natural sistémica o resistencia sistémica adquirida (SAR) contra bacterias patógenas. Además, B. subtilis QST 713, produce tres grupos de metabolitos conocidos como lipopéptidos que actúan de forma sinérgica para destruir tubos germinativos de los patógenos y membranas del micelio (Edgecomb, Manker y Navarro, 2006; EPA, 2007).

En el Perú, desde el año 2005 se ha observado una enfermedad en vid que aparentemente no se encontraba $\mathrm{y}$ que se presenta en plantas de vivero y en plantas jóvenes en el campo. Las características de los síntomas y los primeros aislamientos realizados en la Clínica de Diagnosis de Fitopatología del Departamento Académico de Fitopatología de la Universidad Nacional Agraria La Molina indican que se trataría de la Enfermedad de Petri, motivo por el cual se realizó el siguiente trabajo de investigación con el objetivo de aislar e identificar al agente causal de la Enfermedad de Petri de la vid (Vitis vinifera L.) en el Perú y evaluar, en condiciones de laboratorio, su sensibilidad a algunos productos químicos y controladores biológicos de uso comercial.

\section{Materiales y métodos}

\section{Lugar del estudio}

El trabajo se realizó en el laboratorio, el invernadero y el campo experimental del Departamento Académico de Fitopatología de la Universidad Nacional Agraria La Molina. El período de ejecución fue entre octubre del 2007 y julio del 2008.

\section{Observación de síntomas en plantas de campo y muestreo}

Se inspeccionaron plantas de vid 'Red Globe' en el fundo Don Miguel, en Pisco, y en otras plantaciones ubicadas en la zona de camino de reyes en Ica, en las que se ubicaron y observaron plantas con los síntomas característicos de la Enfermedad de Petri. Las plantas muestreadas tenían entre cuatro y ocho meses de edad, algunas provenientes de vivero y otras ya plantadas en campo. Se cortaron los tallos y raíces, se colocaron en bolsas de polietileno y fueron inmediatamente transportadas al laboratorio de Fitopatología de la UNALM.

\section{Aislamiento e identificación del agente causal}

En el laboratorio, se realizó la observación con un microscopio estereoscópico de la superficie externa de cada muestra de las plantas enfermas con la finalidad de detectar la presencia de cuerpos fructíferos del patógeno. A continuación, las muestras se lavaron con abundante agua corriente, luego se hicieron cortes longitudinales y transversales en los tallos y en las raíces para observar la necrosis presente en la madera. Se cortaron porciones de $5 \mathrm{~cm}$ de diferentes partes de cada planta (raíz, patrón, injerto), se desinfestaron sumergiéndolas en una solución de hipoclorito de sodio al 1,5\% durante un minuto, luego 
se enjuagó con agua destilada estéril y se dejaron secar. Las secciones fueron separadas longitudinalmente y los pequeños trozos de tejido decolorado fueron sembrados en placas petri conteniendo medio Papa Dextrosa Agar suplementado con $0,5 \mathrm{~g} / \mathrm{l}$ de oxitetraciclina (PDAO). Todas las placas fueron incubadas en oscuridad a la temperatura de $25+2{ }^{\circ} \mathrm{C}$ por 15 días. Se obtuvieron cultivos monospóricos a partir de los cuales se sembró en PDAO a $25+2{ }^{\circ} \mathrm{C}$ en oscuridad por dos semanas y luego se pusieron a la luz ultravioleta por una semana más para la producción de las conidias.

La identificación del patógeno se realizó en tres etapas. Primero se procedió a identificar el género, en base a las características de las estructuras fructíferas del patógeno, utilizando inicialmente la clave de Barnett y Hunter (1972) y luego la clave para género hyphomicetes similares a Phaeoacremonium de Mostert et al. (2006). En la segunda etapa, se procedió a identificar la especie en base a las características morfológicas de las estructuras fructíferas del patógeno, utilizando la clave para especies de Phaeoacremonium de Mostert et al. (2006). En la tercera etapa, se confirmó la identidad del hongo aislado por análisis molecular, para lo cual se envió muestras del hongo aislado al Instituto Agroforestal Mediterráneo de la Universidad Politécnica de Valencia España. En el Instituto de Valencia se utilizó la técnica PCR-RFLP del espaciador transcrito interno (ITS) usando los primers específicos para Phaeoacremonium, Pm1-Pm2 y enzimas de restricción BssKI, EcoO109I y HhaI (Aroca y Raposo, 2007), complementado con la secuenciación del fragmento del gen de la $\beta$-tubulina (primers T1 y Bt2b). Las secuencias obtenidas fueron comparadas con las existentes en el banco de genes.

\section{Prueba de patogénesis}

La prueba de patogenicidad se realizó sobre la vid, variedad Red Globe. Se utilizaron estacas de $1 \mathrm{~cm}$ de diámetro de un año de edad aproximadamente. Las estacas se cortaron en segmentos de tallo de $15 \mathrm{~cm}$ de largo, obteniéndose un total de 20. Estos segmentos de tallo fueron desinfestados sumergiéndolos en una solución de hipoclorito de sodio al $1 \%$ por 15 minutos, se enjuagó con agua destilada estéril y se dejó secar. Luego, en cada estaca sana, se realizó un orificio cuadrangular de $3 \mathrm{~mm}$ de lado perforando hasta la médula, a $0,5 \mathrm{~cm}$ debajo del brote. El orificio se llenó con $20 \mu \mathrm{l}$ de suspensión conidias (aproximadamente $10^{3}$ conidia/ml) de un cultivo en PDA de 24 días del hongo aislado e identificado. Los orificios de las estacas del control se llenaron con agua destilada estéril y los inoculados se cubrieron con parafilm. Las estacas se plantaron individualmente en bolsas de polietileno de 7" x 8" que contenían como sustrato una mezcla estéril de compost, arena y tierra en partes iguales. Las estacas inoculadas se mantuvieron en un invernadero, por un período de tres meses, para su brote, crecimiento y expresión de los síntomas. Una vez que las plantas mostraron los síntomas característicos de la Enfermedad de Petri, se procedió a aislar nuevamente el hongo del tejido interno de los tallos de las plantas inoculadas.

\section{Prueba de efectividad de productos químicos y de} biocontroladores en laboratorio

La prueba de control químico en laboratorio se llevó a cabo utilizando la técnica del alimento envenenado. Los tratamientos químicos empleados se observan en la Tabla 1; estos fueron T1: benomil al $1 \%$, T2: Fosetil Aluminio al 2,5 \%o, T3: Procloraz al $1 \%$, T4: Pirimetanil al $1 \%$, T5: Tiofanate metil $1 \%$, T6: Tebuconazol al $1 \%$, T7: Sulfato de Cobre penta-hidratado al 2,5\%o, T8: Fosfonato de potasio al $5 \%$, T9: Proteinato de cobre al 2,5 \%о y T10: Testigo sin fungicida. Se pesaron o midió el volumen correspondiente de cada producto y se vertieron a 100 $\mathrm{ml}$ de PDA líquido a punto de plaqueo, se homogeneizó y se distribuyeron en placas Petri. Para cada tratamiento o producto, se consideraron cuatro placas (repeticiones). Luego que enfrió y solidificó el medio, se colocaron bloques de $0,5 \mathrm{~cm}$ de diámetro de PDA conteniendo micelio del hongo aislado en el centro de cada una de las placas conteniendo el medio de cultivo envenenado; estas fueron incubadas por 24 días a $25+2{ }^{\circ} \mathrm{C}$ y en oscuridad. Se midió en forma interdiaria el diámetro de las colonias a partir del tercer día después de la siembra.

Tabla 1. Tratamientos usados en la prueba de efectividad de productos químicos contra P. parasiticum en laboratorio

\begin{tabular}{|c|l|l|c|}
\hline TRAT. & $\begin{array}{c}\text { PRODUCTOS } \\
\text { QUÍMICOS }\end{array}$ & $\begin{array}{c}\text { NOMBRE } \\
\text { COMERCIAL }\end{array}$ & $\begin{array}{c}\text { CONCENTRACIÓN } \\
\text { (\%o) }\end{array}$ \\
\hline T1 & \multicolumn{1}{|c|}{ Benomil } & Farmate $50 \mathrm{PM}$ & $\mathbf{1 , 0 0}$ \\
\hline $\mathrm{T} 2$ & Fosetil Aluminio & Aliete $80 \mathrm{WP}$ & $\mathbf{2 , 5 0}$ \\
\hline $\mathrm{T} 3$ & Prochloraz & Sportak 45 EC & $\mathbf{1 , 0 0}$ \\
\hline $\mathrm{T} 4$ & Pirimetanil & Scala 40 SC & $\mathbf{1 , 0 0}$ \\
\hline $\mathrm{T} 5$ & Tiofanate metil & Cercobim $\mathrm{M}$ & $\mathbf{1 , 0 0}$ \\
\hline $\mathrm{T} 6$ & Tebuconazol & Folicur EW 250 & $\mathbf{1 , 0 0}$ \\
\hline $\mathrm{T} 7$ & Sulfato de $\mathrm{Cu} 5$ hidrat. & Movil $\mathrm{Cu}$ & $\mathbf{2 , 5 0}$ \\
\hline $\mathrm{T} 8$ & Fosfonato de $\mathrm{K}$ & Fitoprom & $\mathbf{5 , 0 0}$ \\
\hline $\mathrm{T} 9$ & Proteinato de $\mathrm{Cu}$ & Promet $\mathrm{Cu}$ & $\mathbf{2 , 5 0}$ \\
\hline $\mathrm{T} 10$ & Testigo & - & $\mathbf{0 , 0 0}$ \\
\hline
\end{tabular}


La eficacia de los fungicidas evaluados fue obtenida por cálculo del porcentaje de inhibición en el crecimiento de la colonia, usando la siguiente fórmula:

$\mathrm{PI}=\mathrm{C}-\mathrm{T} \times 100$

$\mathrm{C}$

Donde: PI : $\quad$ Porcentaje de inhibición (\%).

C: Crecimiento del diámetro de colonia del testigo $(\mathrm{cm})$.

$\mathrm{T}$ : Crecimiento del diámetro de colonia de cada tratamiento $(\mathrm{cm})$.

En la prueba de control biológico se utilizaron los siguientes controladores biológicos: Trichoderma harzianum (Tricho-D), Trichoderma lignorum (Mycobac) y Bacillus subtilis (Serenade). Se empezó sembrando los controladores en medio PDA y se incubaron a 25 $+2{ }^{\circ} \mathrm{C}$, hasta que el crecimiento de la colonia cubrió la totalidad de la superficie del medio de la placa de Petri. Cuando se tuvieron los aislamientos desarrollados, se realizaron las pruebas de enfrentamiento dual en medio PDA con el hongo patógeno aislado. Con la ayuda de un sacabocado de $5 \mathrm{~mm}$ de radio, se obtuvieron en forma independiente discos procedentes de cada uno de los cultivos de los controladores y del patógeno. Primero se sembró al patógeno en un extremo de la placa, con la finalidad de permitir que este pueda desarrollarse y crecer ya que tiene un crecimiento lento. Después de 14 días (2,5 cm de crecimiento radial) se hizo la siembra de los biocontroladores al otro extremo de la placa, según los tratamientos indicados en la Tabla 2.

Se incubó a $25+2{ }^{\circ} \mathrm{C}$ y se sembraron cuatro repeticiones por controlador. Para los tratamientos testigos se utilizaron placas con medio PDAO, un disco de cada controlador por cada placa a fin de poder observar el desarrollo normal de estos organismos sin la presencia del patógeno. Se hizo lo mismo para el patógeno, es decir un disco del patógeno por placa, con medio PDA, con cuatro repeticiones respectivamente.

Las evaluaciones fueron realizadas diariamente y consistieron en medir el crecimiento radial de ambas colonias en cada placa para luego observar el comportamiento de ambos organismos. Mediante estas pruebas se determinó cuál o cuáles de los controladores biológicos producía una mayor inhibición del crecimiento del patógeno.

Tabla 2. Tratamientos usados en la prueba de enfrentamiento de $P$. parasiticum con los controladores in vitro

\begin{tabular}{cl}
\hline Tratamiento & Descripción \\
\hline 1 & P. parasiticum vs. Trichoderma harzianum \\
2 & P. parasiticum vs. Trichoderma lignorum \\
3 & P. parasiticum vs. Bacillus subtilis \\
4 & Testigo P. parasiticum \\
5 & Testigo T. harzianum \\
6 & Testigo T. lignorum \\
7 & Testigo B. subtilis \\
\hline
\end{tabular}

\section{Resultados y discusión}

\section{Síntomas de la Enfermedad de Petri en vid}

Las plantas de vid afectadas por la enfermedad y que fueron muestreadas, se caracterizaron por ser plantas jóvenes, recién instaladas en campo, o plantas por instalar que provenían del vivero. Las plantas, generalmente, presentaban un crecimiento débil y lento, menor calibre en el tallo, entrenudos más cortos y menor masa foliar. Se observó síntomas foliares como amarilleamiento internervales, seguidos de necrosis (Fig. 1) y defoliación temprana (Fig. 2). En cortes transversales de los tallos de vides afectadas, se observó zonas oscuras, el xilema ennegrecido y unos puntos negros separados con una sustancia brillante que exuda de los vasos (Fig. 3). Asimismo, se notó una reducción de la cantidad de raíces absorbentes y la presencia de lesiones necróticas en las raíces. También se reparó que solamente existía

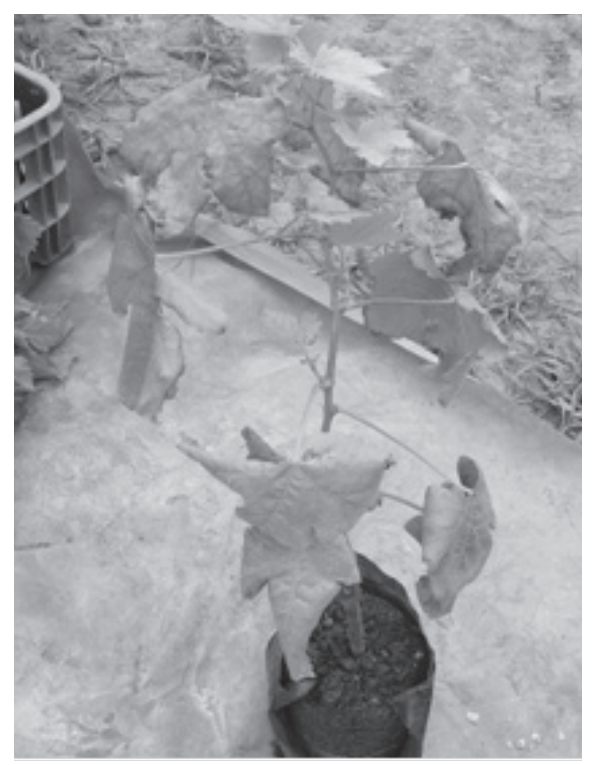

Figura 1. Planta de vivero con necrosis foliar en los bordes.

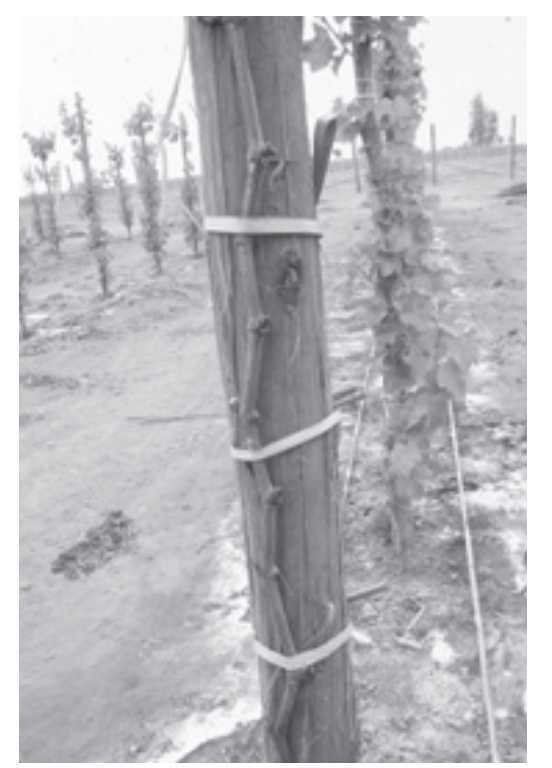

Figura 2. Planta de vid mostrando tallo defoliado. 


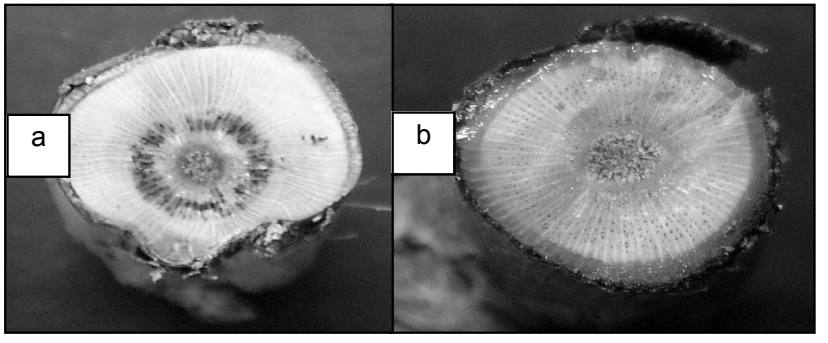

Figura 3. Tallos de vid: (a) Tejido dañado, (b) Tejido sano.

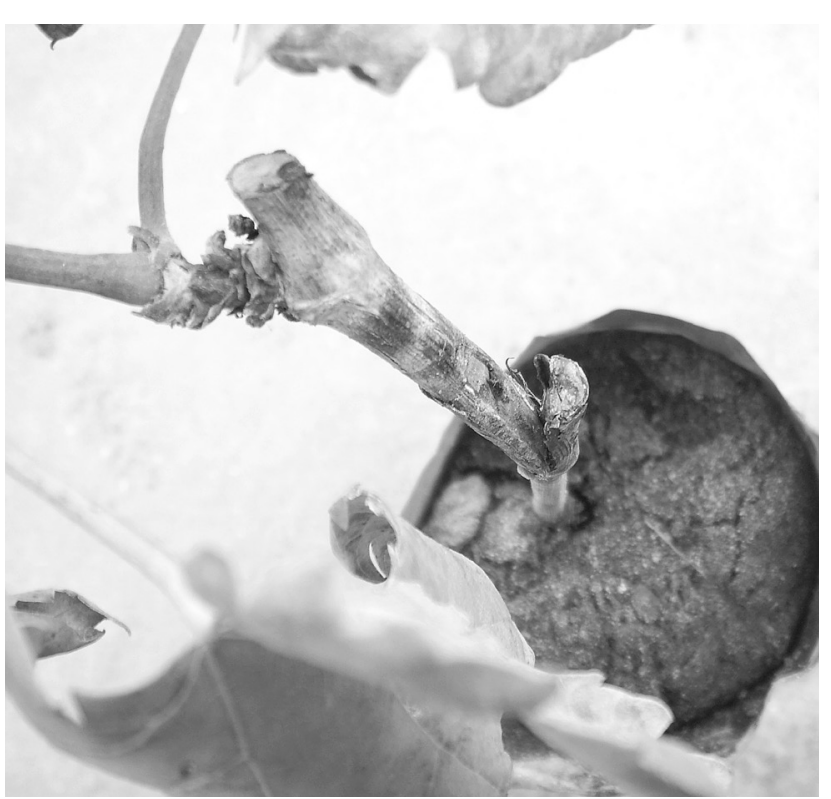

Figura 4. Deficiente unión de injerto en patrón de vid.

una pequeña área de unión en la zona del injerto, en el resto se observó necrosis de tejido (Fig. 4). Las plantas aparentemente en buen estado, ya sea instaladas en el campo o aún mantenidas en sus bolsas, empezaban a mostrar los síntomas y podían llegar a morir en el campo, entre los ocho y los doce meses.

Los síntomas de las plantas afectadas por esta enfermedad y que fueron evaluadas en el campo, coinciden con las descripciones que muchos autores hacen para la Enfermedad de Petri (Mugnai et al., 1999; Morton, 2000; Pascoe y Cottral, 2000; Mostert et al., 2006; Adalat, Whiting, Rooney y Gubler, 2000; Feliciano, Eskalen y Gubler, 2004; Sparapano, Bruno y Graniti, 2001). Actualmente, la llamada Enfermedad de Petri de la vid, es una enfermedad importante para los productores de vid, sobre todo aquellos que han instalado o están instalado nuevas áreas del cultivo. En los campos visitados, donde las plantas se habían instalado recientemente, se observó alrededor de un $25 \%$ de plantas mostrando los síntomas antes descritos; todas esas plantas fueron eliminadas.

\section{Aislamiento e identificación del patógeno}

Al observar bajo el microscopio estereoscopio, la superficie externa de las muestras de las plantas traídas del campo, no se encontró la presencia de cuerpos fructíferos de hongos.
El hongo aislado se identificó utilizando la clave de Barnett y Hunter (1972) y se llegó al género Phialophora, pero se observó ciertas diferencias, sobretodo en la fiálide y collaretes como lo describen Crous, Gams, Wingfield y Van Wyk (1996) por lo que se utilizó la clave para géneros hyphomicetes similares a Phaeoacremonium de Mostert et al. (2006) y se llegó a determinar que corresponde al género Phaeoacremonium. Se determinó la especie como Phaeoacremonium parasiticum (Ajello, Georg \& C.J.K. Wang) W. Gams, Crous \& M.J. Wingf., utilizando la clave para especies de Mostert et al. (2006). La colonia del hongo aislado en medio PDAO es de crecimiento lento, su tasa de crecimiento fue de $1,68 \mathrm{~mm}$ por día a $25+2{ }^{\circ} \mathrm{C}$. Mostert et al. (2006) menciona que Phaeoacremonium parasiticum crece entre 1,31 a 1,44 $\mathrm{mm}$ por día a $25^{\circ} \mathrm{C}$ en MEA, esto es ligeramente menor a lo obtenido; probablemente debido a la variación de la temperatura o al medio de cultivo utilizado. En PDA la colonia es plana, de aspecto algodonoso corto, con el borde entero; encima y en el reverso, después de 10 días, color beige y posteriormente se torna de color pardo, claro, pero hacia los bordes es más claro, amarillo claro. Bajo luz UvA la colonia se pone más oscura, de color olivo negruzco. El micelio es ramificado, hifas septadas, solitarias o formando haces; hifas con verrugas de tamaño entre 1 y $5(2,58)$ m de diámetro; marrón claro a marrón oscuro y 1,5 a $2(1,97) \mu \mathrm{m}$ de ancho. Los conidióforos mayormente largos y ramificados de 27,5 a 67,5 (42,5) $\mu \mathrm{m}$ de largo, de color marrón claro y cada vez más pálidos hacia la punta, 1 a 3 septas, algunas veces conidióforos no ramificados ligeramente hinchado en la base, a menudo teniendo una sola fiálide como célula apical. Las fiálides son terminales o laterales, mayormente monofialídicas, finamente verrucosas, más lisas hacia el ápice, hialino a marrón pálido; collaretes pequeños; fiálides tipo I, II y III, predominando el tipo II, las fiálides disminuyen en grosor poco a poco y terminan en un estrecho cuello. Monstert et al. (2006) trabajó en extracto de malta agar (MEA) y menciona que en esta especie las fiálides predominantes son de tipo III, lo cual difiere de los resultados obtenidos en el presente ensayo, probablemente por efecto del medio de cultivo utilizado, que fue el PDA. Las conidias se presentan en cabezas viscosas, son hialinas, de forma oblongo-elipsoidal, de largo 2,5-7,5 $\mu \mathrm{m}$ y de ancho 1,5$2,5 \mu \mathrm{m}$, con un promedio de $5,51 \times 1,99 \mu \mathrm{m}$; la relación largo/ancho fue de 2,8. El tamaño de las conidias es ligeramente superior al obtenido por Monstert et al. (2006) en largo, ancho y la relación largo/ancho.

Las características antes descritas son muy importantes para la identificación del hongo, sobre todo el tamaño de las verrugas hifales. Monstert et al. (2006), al referirse a este hongo, menciona que es fácilmente identificado en base a la frecuente ocurrencia de verrugas muy prominentes de hasta $3 \mathrm{~mm}$ de diámetro.

El análisis molecular realizado en la Universidad Politécnica de Valencia, España, demostró que existía una similitud de $100 \%$ con la secuencia de $P$. parasiticum (GenBank Accesión AY328379). Estos resultados confirman lo obtenido en la fase previa de identificación en base a la morfología. 


\section{Prueba de patogénesis}

Las plantas de vid, después de 11 semanas de inoculadas con $P$. parasiticum, mostraron síntomas de poco crecimiento, amarilleamiento internerval en las hojas, amarilleamiento hacia los bordes y necrosis en las puntas de hojas; al extraer la planta se observó menor desarrollo radicular. Al aislarlas nuevamente en el medio PDAO, a partir del tejido interno de la planta con síntomas, se obtuvo desarrollo del $P$. parasiticum inoculado. Las plantas no inoculadas que se usaron como testigos, se desarrollaron normalmente. Con esta prueba se corroboró, mediante los postulados de Koch, que Phaeoacremonium parasiticum es uno de los causantes de la Enfermedad de Petri de la vid en el Perú.

La Enfermedad de Petri es producida por varios hongos. Los que se aíslan con mayor frecuencia son Phaeomoniella chlamydospora y varias especies de Phaeoacremonium como mencionan Scheck et al. (1998) y Mugnai (1999), entre otros. Aroca \& Raposo (2007) mencionan que actualmente son 13 las especies de Phaeoacremonium que se han aislado de la vid, entre ellas Phaeoacremonium parasiticum.

En muchos países, asociados a la Enfermedad de Petri, se han encontrado varios de los hongos antes mencionados, por lo que podríamos decir que es posible que en el Perú esté presente no solamente el hongo aislado, $P$. parasiticum, sino que existan otras especies como Phaeomoniella chlamydospora u otras especies de Phaeoacremonium. P. parasiticum ha sido aislado de la vid en Argentina (Dupont, Magnin, Cesari y Gatica, 2002), Chile (Auger, Esterio, Perez, Gubler y Eskalen, 2004), USA (Monstert et al., 2006), España (Aroca et al., 2006) y otros países del mundo. Probablemente, si este hongo no ha estado en el país ha ingresado proveniente de los países en los que esta enfermedad está presente y de los cuales se importa material vegetativo utilizado para producir plantones de vid en los viveros.

\section{Prueba de efectividad de productos químicos y de biocontroladores en laboratorio}

Los resultados de la prueba de productos químicos en laboratorio se muestran en la Tabla 3, donde se puede observar los valores del crecimiento final de las colonias de los diferentes tratamientos, a los 24 días.
El pirimetanil y el sulfato de cobre pentahidratado inhibieron el crecimiento del hongo en $100 \%$ seguido de fosetil alumnio que inhibió 97,35\%. La colonia del hongo en el medio con fosetil alumnio recién empieza a dar indicios de crecimiento alrededor del día 18 después de sembrado. Las demás colonias, con excepción de las que fueron sembradas en medio con Pirimetanil y Sulfato de cobre pentahidratado, empezaron a crecer prácticamente desde que fueron sembradas uno o dos días después. El crecimiento de las colonias sembradas en Tiofanate metil y Tebuconazol y del testigo fue casi similar; mientras que el de las demás colonias fue menor. Los resultados de la prueba de Duncan $(0,05)$ para los diámetros de crecimiento final de las colonias del hongo en los diferentes tratamientos, indican que el crecimiento del hongo en el medio con Pirimetanil, Sulfato de cobre pentahidratado y Fosetil-Al no difieren estadísticamente; aunque los dos primeros no crecieron nada, el tercero sí tuvo indicios de crecimiento $(2 \mathrm{~mm})$, los demás tratamientos crecieron más.

El pirimetanil actúa como inhibidor de la germinación de esporas y formación de apresorio (Fritz et al., 1997), probablemente en el medio tuvo esta acción pero además también actuó en la inhibición del crecimiento de micelio, porque no se logró observar ningún crecimiento del hongo sobre este medio.

El sulfato de cobre inhibe el desarrollo de esporas, pero además su acción podría estar a nivel de la presencia de cobre en el medio, en cantidades tóxicas para el hongo, por lo que impidió su desarrollo. OMRI (2001) atribuye la acción tóxica del cobre a su capacidad para desnaturalizar las proteínas celulares y para desactivar el sistema enzimático de hongos.

El fosetil alumnio permitió indicios de crecimiento del hongo a partir del día 18 después de la siembra hasta el día 24 en que se evaluó. Este fungicida actúa por un mecanismo basado en la actividad fungicida del ácido fosforoso (Fenn \& Coffey, 1984), también puede atacar indirectamente a los hongos por los polifenoles, en particular el resveratrol que es producido en la planta por inducción de este fungicida (Mazzullo et al., citado por Calzanaro, Di Marco y Cesari, 2004). En el medio PDA, probablemente, la acción del fungicida contra el hongo se

Tabla 3. Diámetro de crecimiento y porcentaje de inhibición de las colonias de P. parasiticum en la prueba de control químico in vitro a los 24 días después de la siembra, ordenados según la Prueba de Duncan $(0,05)$

\begin{tabular}{llcc}
\hline TRAT. & PRODUCTOS QUÍMICOS & DIÁMETRO (cm) & PORCENTAJE DE INHIBICIÓN \\
\hline T7 & Sulfato de Cu 5 hidrat. & $0,00 \mathrm{~A}$ & 100 \\
T4 & Pirimetanil & $0,00 \mathrm{~A}$ & 100 \\
T2 & Fosetil - Al & $0,20 \mathrm{AB}$ & 97,35 \\
T3 & Prochloraz & $0,50 \mathrm{~B}$ & 93,38 \\
T8 & Fosfonato de K & $1,60 \mathrm{C}$ & 78,81 \\
T1 & Benomil & $1,88 \mathrm{C}$ & 75,1 \\
T9 & Proteinato de Cu & $2,76 \mathrm{D}$ & 63,44 \\
T5 & Tiofanate metil & $5,90 \mathrm{E}$ & 21,85 \\
T6 & Tebuconazol & $6,15 \mathrm{E}$ & 18,54 \\
T10 & Testigo & $7,55 \mathrm{~F}$ & 0 \\
\hline
\end{tabular}


debió al ácido fosforoso. Este fungicida en aplicaciones en campo tiene una duración entre dos a seis meses debido a la inducción de resistencia en la planta; pero en el medio de cultivo el acido fosforoso, probablemente, pierde su acción en menor tiempo, así se explicarían los indicios de crecimiento del hongo en el medio con este fungicida.

En la prueba de control biológico, al enfrentar T. harzianum con $P$. parasiticum, la colonia de $P$. parasiticum tuvo un crecimiento algo similar al de su testigo hasta el tercer día después de inocular T. harzianum; a partir de este día detuvo su crecimiento por entrar en contacto con el controlador. Por otro lado, T. harzianum continuó con su crecimiento sobre la colonia de $P$. parasiticum, pero con una menor tasa de crecimiento, por lo que llegó a cubrirlo completamente a los 10 días. Conforme avanzaba el ataque del controlador sobre el patógeno, se observó la desaparición del micelio del patógeno y la esporulación del controlador sobre el patógeno. Al enfrentar $T$. lignorum con P. parasiticum, el comportamiento de ambos hongos fue similar al caso anterior. En el enfrentamiento de Bacillus subtilis vs. $P$. parasiticum, la colonia de $P$. parasiticum tuvo un crecimiento algo similar al de su testigo hasta que entró en contacto, al cuarto día, con las toxinas de la bacteria en que detuvo su crecimiento y empezó a cambiar de color a un marrón negruzco en la zona de contacto (Tabla 4).

Los controladores mostraron un claro efecto antagónico contra $P$. parasiticum en los cultivos duales realizados in vitro. En el caso de los Trichoderma, sobrecrecieron y redujeron totalmente la colonia del patógeno y mostraron un marcado efecto hiperparasítico, que se manifiesta por la inhibición del crecimiento micelial, no sólo por compartir el mismo sustrato sino también porque estos controladores producen antibióticos y enzimas ( $\beta-1,3-$ glucanasa, quitinasa, proteasa y celulasa) degradadores de la pared celular y que juegan un importante papel en el micoparasitismo (Lorito et al. 1993; Harman, 2006). En el caso de B. subtilis, se observó antagonismo, probablemente debido a la acción de los lipopéptidos de la bacteria o a la competencia de nutrientes, ya que en el producto comercial también viene la bacteria en una concentración muy baja (EPA, 2006).

Tabla 4. Radio de las colonias de P. parasiticum y de los biocontroladores en la prueba de control biológica in vitro

\begin{tabular}{|c|c|c|c|c|c|c|}
\hline \multirow[t]{2}{*}{ ENFRENTAMIENTO } & \multirow[t]{2}{*}{$\begin{array}{c}\text { TRATAMIENTO } \\
\text { CORRESPONDIENTE }\end{array}$} & \multirow[t]{2}{*}{$\begin{array}{l}\text { ORGANISMO } \\
\text { EVALUADO }\end{array}$} & \multicolumn{4}{|c|}{$\begin{array}{c}\text { Días después de la } \\
\text { siembra del controlador } \\
\text { (Radio en } \mathrm{cm} \text { ) }\end{array}$} \\
\hline & & & 1 & 2 & 3 & 4 \\
\hline \multirow{4}{*}{$\begin{array}{l}\text { P. parasiticum vs. T. } \\
\text { harzianum }\end{array}$} & $\mathrm{T} 1$ & $\begin{array}{l}\text { P. parasiticum } \\
\text { (enfrentado) }\end{array}$ & 2,55 & 2,65 & 2,73 & 2,73 \\
\hline & $\mathrm{T} 1$ & $\begin{array}{l}\text { T. harzianum } \\
\text { (enfrentado) }\end{array}$ & 1,43 & 3,35 & 4,40 & 5,30 \\
\hline & $\mathrm{T} 4$ & $\begin{array}{l}\text { P. parasiticum } \\
\text { (testigo) }\end{array}$ & 2,60 & 2,70 & 2,80 & 2,95 \\
\hline & T5 & $\begin{array}{l}\text { T. harzianum } \\
\text { (testigo) }\end{array}$ & 1,65 & 3,60 & 5,65 & 7,70 \\
\hline \multirow{4}{*}{$\begin{array}{l}\text { P. parasiticum vs. T. } \\
\text { lignorum }\end{array}$} & $\mathrm{T} 2$ & $\begin{array}{l}\text { P. parasiticum } \\
\text { (enfrentado) }\end{array}$ & 2,48 & 2,58 & 2,68 & 2,68 \\
\hline & $\mathrm{T} 2$ & $\begin{array}{l}\text { T. lignorum } \\
\text { (enfrentado) }\end{array}$ & 1,48 & 3,45 & 4,35 & 5,40 \\
\hline & $\mathrm{T} 4$ & $\begin{array}{l}\text { P. parasiticum } \\
\text { (testigo) }\end{array}$ & 2,60 & 2,70 & 2,80 & 2,95 \\
\hline & T6 & $\begin{array}{l}\text { T. lignorum } \\
\text { (testigo) }\end{array}$ & 1,70 & 3,70 & 5,73 & 7,70 \\
\hline \multirow{4}{*}{$\begin{array}{l}\text { P. parasiticum vs. B. } \\
\text { subtilis }\end{array}$} & $\mathrm{T} 3$ & $\begin{array}{l}\text { P. parasiticum } \\
\text { (enfrentado) }\end{array}$ & 2,55 & 2,68 & 2,83 & 2,98 \\
\hline & $\mathrm{T} 3$ & $\begin{array}{l}\text { B. subtilis } \\
\text { (enfrentado) }\end{array}$ & 4,20 & 4,20 & 4,20 & 4,20 \\
\hline & $\mathrm{T} 4$ & $\begin{array}{l}\text { P. parasiticum } \\
\text { (testigo) }\end{array}$ & 2,60 & 2,70 & 2,80 & 2,95 \\
\hline & $\mathrm{T} 7$ & $\begin{array}{l}\text { B. subtilis } \\
\text { (testigo) }\end{array}$ & 4,20 & 4,20 & 4,20 & 4,20 \\
\hline
\end{tabular}




\section{Conclusiones}

Se identificó al hongo causante de la Enfermedad de Petri de la vid como Phaeoacremonium parasiticum (Ajello, Georg \& C.J.K. Wang) W. Gams, Crous \& M.J. Wing, y los fungicidas comerciales que mejor inhibieron su crecimiento fueron: pirimetanil y sulfato de cobre pentahidratado, ambos en $100 \%$, y fosetil aluminio en $97,35 \%$. Los tres controladores biológicos evaluados, $T$. harzianum, T. lignorum y B. subtilis, tuvieron un efecto controlador sobre $P$. parasiticum pues inhibieron su crecimiento en $65,9 \%, 66,5 \%$ y $62,5 \%$, respectivamente.

\section{Literatura citada}

Adalat, K.; Whiting, C.; Rooney, S. y Gubler, W. D. 2000. Pathogenicity of three species of Phaeoacremonium spp. on grapevine in California. Phytopathologia Mediterranea, 39: 92-99.

Agrios, G. 2005. Plant Pathology. (5ta. Edición). USA: Elsevier Academic Press.

Auger, J.; Esterio, M.; Perez, I.; Gubler, W. y Eskalen, A. 2004. First report of Phaeomoniella chlamydospora on Vitis vinifera and french american hybrids in Chile. Plant Disease, 88: 1285.

Calzanaro, F.; Di Marco, S. y Cesari, A. 2004. Benefit of fungicide treatment after trunk renewal of vines with different types of necrosis. Phytopathologia Mediterranea, 43: 116-124.

Crous, P.; Gams, W.; Wingfield, M. y Van Wyk, P. 1996. Phaeoacremonium gen. nov. associated with wilt and decline diseases of woody hosts and human infections. Mycologia 88(5): 786-796.

Dupont, J.; Magnin, S.; Cesari, C. y Gatica, M. 2002. ITS and $\beta$-tubulin markers help delineate Phaeoacremonium species, and the occurrence of $P$. parasiticum in grapevine disease in Argentina. Mycological Research, 106 (10): 1143-1150.

Edgecomb, D.; Manker, D. y Navarro, M. 2006. Serenade biofungicide (Bacillus subtilis, strain QST 713), a new biological tool for organic and integrated sigatoka (Mycosphaerella fijiensis) control programs in bananas. Davis, USA: AgraQuest. Disponible en: http://www.inra. fr/ciab/papers/EdgecombD.pdf

Eskalen, A. y Gubler, D. 2001. Associated of spores of Phaeomoniella chlamydospora, Phaeoacremonium inflatipes, and Pm. aleophilum with grapevine cordons in California. Phytopathologia Mediterranea, 40, Suplement, S429-S432.

Feliciano, A. J.; Eskalen, A. y Gubler, W.D. 2004. Differential susceptibility of three grapevine cultivars to Phaeoacremonium aleophilum and Phaeomoniella chlamydospora in California. Phytopathologia Mediterranea, 43: 66-69.

Fenn, M.E. y Coffey, M.D. 1984. Studies on the in vitro and in vivo antifungal activity of fosetyl Al and phosphorous acid. Phytopathology, 74(5): 606-611.

Fritz, R., Lanen, C., Colas, V. y Leroux, P. 1997. Inhibition of methionine biosynthesis in Botrytis cinerea by the anilinopyrimidine fungicide pyrimethanil. Pesticide Science, 49: 40-46.

Harman, G.E. 2006. Overview of mechanisms and uses of Trichoderma spp. Phytopathology, 96(2): 190-194.

Lorito, M.; Harman, G.E.; Hayes, C.K.; Broadway, R.M.; Trasmo, A.; Woo, S.L. y Pietro, A. 1993. Chitinolytic enzymes produced by Trichoderma harzianum: Antifungal activity of purified endochitinase and chitobiosidase. Phytopathology, 83: 302-307. Mostert, L.; Groenewald, J.; Summerbell, R.; Gams, W. y Crous, P. 2006. Taxonomy and Pathology of Togninia (Diaporthales) and its Phaeoacremonium Anamorphs. Centraalbureau voor Schimmelcultures. Utrecht, The Netherlands: Fungal Biodiversity Centre.

Mostert, L.; Halleen, F.; Fourie, P. y Crous, P. 2006. A review of Phaeoacremonium species involved in Petri disease and esca of grapevines. Phytopathologia Mediterranea, 45: S12-S29.

Morton, L. 2000. Viticulture and grapevine declines: lessons of black goo. Phytopathologia Mediterranea, 39, 59-67.

Mugnai, L.; Graniti, A. y Surico, G. 1999. Esca (black measles) and brown word-streaking: two old and elusive disease of grapevines. Plant Disease, 83(5): 404-416.

Organic Materials Review Institute (OMRI). (2001). Copper Sulfate as algicide and invertebrate pest control. Disponible en: http://www.omri.org/coppersulfate.pdf

Pascoe, I. y Cottral, E. 2000. Developments in grapevine trunk diseases research in Australia. Phytopathologia Mediterranea, 39: 68-75.

Porter, M. 2005. Consensus Reached on the Cause of Petri's Disease. Wine Business, XII (10). Disponible en:

http://www.winebusiness.com/Html/MonthlyArticle. cfm?dataId $=41248$

Scheck, H.J.; Vasquez, S.J. y Gubler, W.D. 1998. First report of three Phaeoacremonium spp. causing young grapevine decline in California. Plant Disease, 82: 590. Sparapano, L.; Bruno, G. y Graniti, A. 2001. Threeyear observation of grapevines cross-inoculated with esca-associated fungi. Phytopathologia Mediterranea, 40, Supplement, S376-S386. 